\title{
Computer assisted retraining of attentional impairments in patients with multiple sclerosis
}

\author{
A M Plohmann, L Kappos, W Ammann, A Thordai, A Wittwer, S Huber, Y Bellaiche, \\ J Lechner-Scott
}

\begin{abstract}
Objective-To evaluate the efficacy of a computer based retraining of specific impairments of four different attentional domains in patients with multiple sclerosis.

Methods-Twenty two outpatients with multiple sclerosis received consecutively a specific training comprising 12 sessions in each of the two most impaired attention functions. The baseline of attentional deficits, the performance after each training period, and the course of performance in the next nine weeks was assessed by a computerised attention test battery. Additionally, the impact of the training on daily functioning was evaluated with a self rating inventory.

Results-Subgroups of patients with multiple sclerosis showing different patterns of attentional impairment could be separated. Significant improvements of performance could almost exclusively be achieved by the specific training programmes. The increase of performance remained stable for at least nine weeks. For quality of life patients reported less attention related problems in everyday situations.

Conclusions-In patients with multiple sclerosis it seems worthwhile to assess attentional functions in detail and to train specific attention impairments selectively. (F Neurol Neurosurg Psychiatry 1998;64:455-462)
\end{abstract}

Keywords: multiple sclerosis; attention; cognitive deficits; cognitive rehabilitation

Department of

Neurology, University

Hospital, CH-4031

Basel, Switzerland

A M Plohmann

L Kappos

W Ammann

A Thordai

A Wittwer

$S$ Huber

Y Bellaiche

J Lechner-Scott

Correspondence to: Professor L Kappos, Department of Neurology,

Kantonsspital, Basel,

CH-4031 Basel, Switzerland.

Received 10 May 1997 and in revised form 23

September 1997

Accepted 7 October 1997
Neuropsychological investigations have shown that there is some degree of cognitive deterioration in $45 \%-65 \%$ of patients with multiple sclerosis. ${ }^{1-4}$ These cognitive deficits seem to share numerous characteristics associated with the syndrome of "subcortical dementia"..$^{-9}$ The presumed mechanism underlying subcortical dementia is disconnection of pathways linking subcortical structures with cortical areas or the limbic system. The cardinal neurobehavioural features consist of a slowing of mental processing, forgetfulness (free recall memory tasks being more impaired than recognition tasks), impaired abstract reasoning, and changes in mood and personality in the context of relatively preserved intellectual and language functions. ${ }^{10}{ }^{11}$ Recent studies, however, disclose deficits related to multiple sclerosis on tasks of verbal fluency, verbal discourse, writing, and concept definition. ${ }^{12} 13$
Neuropsychological disturbances seem to have a major impact on the quality of life of patients with multiple sclerosis. As Rao et $a l^{14}$ pointed out, cognitively impaired patients with multiple sclerosis, as opposed to merely physically disabled patients with the disease, were found to be less likely to be employed, engaged in fewer social and vocational activities, reported more sexual dysfunction, experienced greater difficulties in performing routine household tasks, and were more vulnerable in developing increased psychopathology.

Although the negative impact of neuropsychological deficits on social functioning is becoming more and more a focus of attention very few findings are available regarding treatment and rehabilitation of these deficits. As one of only a few studies Smits et $a l^{15}$ found that 4-aminopyridine, a potassium channel blocker, had no effect on the performance of patients with multiple sclerosis in neuropsychological tests. Foley et $a l^{16}$ have recently described a comprehensive psychological approach for managing the communication problems of cognitively impaired patients with multiple sclerosis. Jonsson et $a l^{17}$ offered a specific cognitive treatment comprising cognitive training and neuropsychotherapy and compared this with a non-specific mental stimulation. They found an improvement of the total group of patients with multiple sclerosis on several cognitive factors and tests, which could be explained by a retest effect or a non-specific treatment effect. Interestingly, on the Beck depression inventory (BDI) the specific cognitive treatment group reported significantly less depression, whereas the non-specific treatment group rated themselves as significantly more depressed.

The present study aims at evaluating the effects of a specific computer based retraining of four attentional functions on cognitive measures in patients with multiple sclerosis with mild to moderate cognitive dysfunction. We have focused on attentional disorders as attention (or to use a more inclusive term, information processing) represents a controlling and integrating function with implications for nearly all other cognitive systems. Furthermore, attention has been recognised as possibly the most prominent aspect of cognition affected in some patients with multiple sclerosis. As shown in various studies attention is not a unitary phenomenon but has to be subdivided into at least four different components: on the one hand alertness and sustained attention (vigilance), both referring to the 


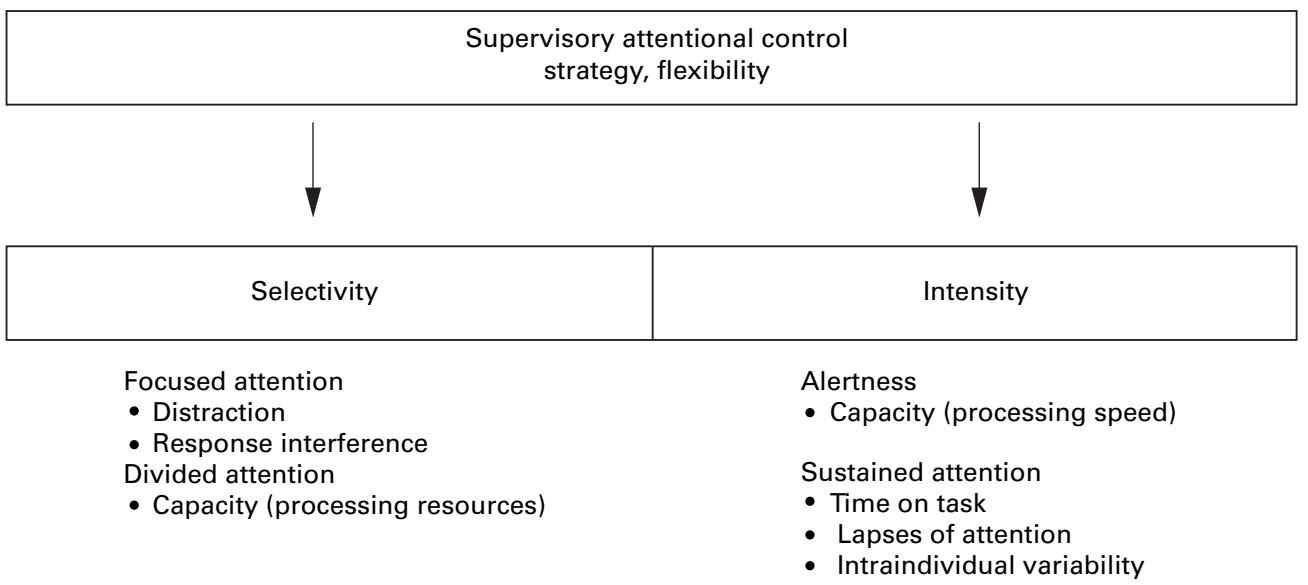

Scheme of a theoretical framework of attention, adopted from Van Zomeren and Brouwer ${ }^{32}$.

intensity aspect of attention, on the other hand selective attention and divided attention as approaches to the selectivity aspect (fig 1)..$^{18-20}$ According to Posner and Rafal ${ }^{20}$ alertness refers to a generalised physical and mental state of arousal preparedness to respond. Alertness can be subdivided into two different types: tonic alertness, which refers to the diurnal fluctuation in wakefulness and performance and phasic alertness, the sudden increased attentiveness which immediately follows a warning signal which the organism knows will soon require a rapid response. Selective attention represents the ability to focus on one source or type of information to the exclusion of others.

Table 1 Descriptive statistics of the patient sample

\begin{tabular}{llll}
\hline & $\begin{array}{l}\text { No of } \\
\text { patients }\end{array}$ & Mean (SD) & Range \\
\hline Total & 22 & & \\
Age (y) & & $44.6(11.4)$ & $25-70$ \\
$\begin{array}{l}\text { Education (y) } \\
\text { clinical indices: }\end{array} \quad 13.0(2.0)$ & $10-18$ \\
$\quad \begin{array}{l}\text { Multiple sclerosis course (n): } \\
\quad \text { Primary chronic }\end{array}$ & & & \\
$\quad$ progressive & 1 & & \\
$\quad$ Secondary chronic & & & \\
$\quad$ progressive & 5 & & \\
$\quad$ Relapsing-remitting & 16 & $16.6(9.1)$ & $4-40$ \\
$\quad$ Duration of disease (y) & & $3.8(1.8)$ & $2-8$ \\
$\quad$ Kurtzke EDSS & & & \\
\hline
\end{tabular}

Tasks involving divided attention require attention to be divided or shared between two or more sources or kinds of information, or two or more mental operations. ${ }^{21}$ Sustained attention or vigilance refers to the ability to attend over long and generally unbroken periods of time for the purpose of detecting and responding to relevant stimuli.

Although studies on the efficacy of rather non-specific attention retraining for patients with diffuse brain damage (patients with head trauma) showed effects on different attention and even intellectual functions, ${ }^{22}{ }^{23}$ corresponding studies concerning patients with more localised lesions such as some patients with stroke or head trauma disclosed that it might be advantageous to train different attention functions specifically. ${ }^{24}{ }^{25}$ For these reasons we used a computer assisted attention training software (AIXTENT) designed by Sturm et $a l,{ }^{26}$ which contains programmes for each of the four attention domains mentioned before. The programmes were constructed like computer games and aimed to represent daily attention situations. They have proved to be an effective tool in rehabilitation of attentional impairments in patients with stroke. $^{27}$

Table 2 Median (range) before $\left(T_{1-3}\right.$; baseline) and after $\left(T_{\downarrow}\right)$ the first training

\begin{tabular}{|c|c|c|c|c|c|c|c|c|c|}
\hline \multirow[b]{3}{*}{ Control test (TAP) } & & \multicolumn{8}{|c|}{ Training group } \\
\hline & & \multicolumn{2}{|c|}{ Alertness $(n=7)$} & \multicolumn{2}{|c|}{ Divided attention $(n=8)$} & \multicolumn{2}{|c|}{ Selective attention $(n=6)$} & \multicolumn{2}{|l|}{ Vigilance $(n=2)$} \\
\hline & & $T_{1-3}$ & $T_{4}$ & $T_{1-3}$ & $T_{4}$ & $T_{1-3}$ & $T_{4}$ & $T_{1-3}$ & $T_{4}$ \\
\hline \multicolumn{10}{|l|}{ Alertness: } \\
\hline Simple & RT & $33(27-37)$ & $44(33-55)^{\star}$ & $46(41-61)$ & $45(35-57)$ & $48(40-70)$ & $57(43-64)$ & $53(49-57)$ & $57.5(54-61)$ \\
\hline Cued & RT & $37(28-45)$ & $43(32-52)$ & $50.5(38-60)$ & $48.5(39-61)$ & $47(37-66)$ & $56(47-62)$ & $51.5(49-54)$ & $54(54-54)$ \\
\hline \multirow[t]{3}{*}{ Divided attention } & RT & $43(32-47)$ & $43(30-56)$ & $41.5(30-48)$ & $45.5(32-56)^{\star}$ & $37.5(30-46)$ & $44(35-60)$ & $45.5(43-48)$ & $42.5(41-44)$ \\
\hline & Errors & $1(1-3)$ & $2(0-2)$ & $1(0-3)$ & $0.5(0-2)$ & $0.5(0-2)$ & $0.5(0-2)$ & $0(0-0)$ & $0.5(0-1)$ \\
\hline & Omissions & $3(1-8)$ & $3(1-7)$ & $2.5(0-9)$ & $2.5(0-6)$ & $2(0-6)$ & $1(0-6)$ & $1.5(0-2)$ & $0(0-0)$ \\
\hline \multicolumn{10}{|c|}{ Selective attention: } \\
\hline \multirow[t]{2}{*}{ Go/no-go } & RT & $42(27-53)$ & $45(30-66)$ & $45.5(20-60)$ & $46.5(20-72)$ & $41(20-56)$ & $51.5(43-70)^{\star}$ & $49.5(42-57)$ & $47.5(35-60)$ \\
\hline & Errors & $0(0-0)$ & $0(0-2)$ & $0(0-1)$ & $0(0-1)$ & $0.5(0-2)$ & $0(0-1)$ & $0(0-0)$ & $0(0-0)$ \\
\hline \multirow[t]{2}{*}{ Incompatibility } & RT & $31(20-42)$ & $36(20-48)^{\star}$ & $45(20-63)$ & $45(20-63)$ & $26.5(20-58)$ & $37.5(30-66)^{\star}$ & $58(57-59)$ & $60.5(56-65)$ \\
\hline & Errors & $3(2-6)$ & $3(1-6)$ & $2.5(0-10)$ & $1(0-3)$ & $3(1-7)$ & $3.5(0-12)$ & $1(1-1)$ & $2(0-4)$ \\
\hline \multirow{2}{*}{ Flexibility } & RT & $42(34-54)$ & $44(36-60)^{\star}$ & $50(29-64)$ & $56.5(34-72)^{\star}$ & $44.5(20-56)$ & $52.5(28-70)^{\star}$ & $54.5(49-60)$ & $56(51-61)$ \\
\hline & Errors & $4(1-8)$ & $3(0-12)$ & $2.5(0-20)$ & $2(0-13)$ & $5(1-18)$ & $2.5(0-4)$ & $3(1-5)$ & $1(0-2)$ \\
\hline \multirow[t]{3}{*}{ Vigilance } & RT & $48(42-57)$ & $52(39-61)$ & $52(40-63)$ & $50(39-61)$ & $50.5(46-64)$ & $56(45-66)$ & $51.5(48-55)$ & $54.5(51-58)$ \\
\hline & Errors & $1(0-2)$ & $2(0-3)$ & $1(0-8)$ & $1.5(0-11)$ & $0.5(0-9)$ & $0(0-3)$ & $0.5(0-1)$ & $0(0-0)$ \\
\hline & Omissions & $1(0-10)$ & $5(0-10)$ & $3(0-13)$ & $2(0-15)$ & $1.5(1-4)$ & $1.5(0-3)$ & $7(4-11)$ & $2(2-2)$ \\
\hline
\end{tabular}

${ }^{\star} \mathrm{p}<0.05 ; \mathrm{t}_{1-3} v \mathrm{t}_{4}$, Wilcoxon signed ranks test.

Values for reaction time (RT) are T scores based on a normative sample ( $\mathrm{n}=200$ healthy subjects).

$\mathrm{t}_{1-3}=$ Median of $\mathrm{t}_{1}, \mathrm{t}_{2}$, and $\mathrm{t}_{3}$. 
Table 3 Changes of performance after the first training

\begin{tabular}{lllll}
\hline & & \multicolumn{2}{c}{ Training group p values } \\
\cline { 3 - 4 } Control test (TAP) & & Alertness & $\begin{array}{l}\text { Divided } \\
\text { attention }\end{array}$ & $\begin{array}{l}\text { Selective } \\
\text { attention }\end{array}$ \\
\hline Alertness: & RT & & & \\
Simple & RT & $0.018^{\star}$ & 0.127 & 0.225 \\
Cued & RT & 0.834 & 0.671 & 0.172 \\
Divided attention & Errors & 0.655 & $0.028^{\star}$ & 0.068 \\
& Omissions & 1.0 & 0.163 & 0.783 \\
Selective attention: & RT & 0.309 & 0.739 & 0.578 \\
Go/no-go & Errors & 0.317 & 0.115 & $0.028^{\star}$ \\
Incompatibility & RT & $0.041^{\star}$ & 0.764 & 0.157 \\
Flexibility & Errors & 0.683 & 0.206 & $0.046^{\star}$ \\
Vigilance & RT & $0.017^{\star}$ & $0.012^{\star}$ & 0.588 \\
& Errors & 0.751 & 0.206 & $0.028^{\star}$ \\
& RT & 0.446 & 0.672 & 0.249 \\
& Errors & 0.198 & 0.462 & 1.0 \\
& Omissions & 0.518 & 0.491 & 0.480 \\
\hline
\end{tabular}

Because of the small sample size, no statistical analysis was done for the vigilance group. $p$ Values are differences between $t_{1-3}$ and $t_{4}$ (Wilcoxon matched pairs test).

^Significant differences.

\section{Methods}

PATIENTS

Outpatients with multiple sclerosis who complained of cognitive disturbances were selected according to the following criteria: clinically definite multiple sclerosis, ${ }^{28}$ stable phase of the disease for three months before inclusion (no relapse in this period), no steroid treatment in the four weeks before inclusion, and no change in immunosuppressive or immunomodulating treatment for the past six months. To avoid interference of visual deficits, visual acuity, visual fields and eye movement disorders were tested in the frame of a standardised neurological assessment. If deficits concerning visual acuity or visual fields were suspected, patients were referred for a comprehensive ophthalmological investigation including Goldman perimetry. Patients with interfering visual disturbances or severe motor disorders of the arms, hearing loss, psychiatric history, drug or alcohol misuse, or nervous system disorders other than multiple sclerosis were excluded from the study.

For neuropsychological deficits, only patients showing a percentile score $<25$ (with respect to reaction times) or exceeding the cut off point (of errors or omissions) in at least two of the four attention functions were referred for the training.

TESTS APPLIED

The main outcome criterion was a selection of seven subtests derived from the attention test battery (TAP-1.02c $)^{29}$ :

\section{Tonic and phasic alertness}

The examination includes a simple and a cued reaction time task with a visual test stimulus and an acoustic cue. The simple reaction time has been shown to be a valid measure of processing speed. $^{30}{ }^{31}$ A phasic change of alertness can be assessed by comparing reaction time with (cued RT) and without (simple RT) a warning signal. $^{2032} 33$ The present test consists of four trials in an ABBA design each containing 20 presentations $(\mathrm{A}=$ without cue, $\mathrm{B}=$ with cue $)$.

\section{Divided attention}

Divided attention can be operationally defined by combining two or more tasks in one test. ${ }^{32}$ For this it should be clear that the multiple tasks evoke no structural interference. ${ }^{34}$ In this subtest a visual and an acoustic task are presented simultaneously. The visual task consists of crosses that appear in a random configuration in a $4 \times 4$ matrix. The subject has to detect whether the crosses form the corners of a square. In the acoustic task the subject has to detect an irregularity in a regular sequence of high and low beeps.

\section{Go/no-go}

Focused attention involves selectivity in perceiving and responding and is commonly referred to as concentration. The present task was designed to assess response inhibition to irrelevant stimuli as well as reaction time in response selection paradigms (choice reaction time). Five stimuli (squares filled in with different patterns) are employed in this task, two of them being critical. They have to be responded to by pushing a switch.

\section{Incompatibility}

The aim of this examination is an assessment of the capacity of focused attention-that is, to reject irrelevant, automatically processed infor-

Table 4 Median (range) before $\left(T_{4}\right)$ and after $\left(T_{5}\right)$ the second training

\begin{tabular}{|c|c|c|c|c|c|c|c|c|c|}
\hline \multirow[b]{3}{*}{ Control test (TAP) } & & \multicolumn{8}{|c|}{ Training group } \\
\hline & & \multicolumn{2}{|c|}{ Alertness $(n=4)$} & \multicolumn{2}{|c|}{ Divided attention $(n=10)$} & \multicolumn{2}{|c|}{ Selective attention $(n=7)$} & \multicolumn{2}{|c|}{ Vigilance $(n=1)$} \\
\hline & & $T_{4}$ & $T_{5}$ & $T_{4}$ & $T_{5}$ & $T_{4}$ & $T_{5}$ & $T_{4}$ & $T_{5}$ \\
\hline \multicolumn{10}{|l|}{ Alertness: } \\
\hline Simple & RT & $44(35-64)$ & $55(40-59)$ & $51(33-62)$ & $48.5(34-70)$ & $55(34-61)$ & $58(34-86)$ & 47 & 43 \\
\hline Cued & RT & $43(39-61)$ & $53(42-59)$ & $48.5(32-62)$ & $47.5(30-67)$ & $52(37-61)$ & $56(44-93)$ & 48 & 50 \\
\hline \multirow{3}{*}{ Divided attention } & RT & $47(39-60)$ & $44(42-80)$ & $43.5(30-53)$ & $41.5(31-51)$ & $43(32-56)$ & $44(27-56)$ & 47 & 32 \\
\hline & Errors & $0(0-2)$ & $0(0-2)$ & $1(0-2)$ & $0.5(0-2)$ & $1(0-2)$ & $1(0-2)$ & 0 & 1 \\
\hline & Omissions & $3(0-6)$ & $1.5(0-2)$ & $2.5(0-7)$ & $1(0-7)$ & $1(0-4)$ & $1(0-11)$ & 3 & 3 \\
\hline \multicolumn{10}{|l|}{ Selective attention: } \\
\hline \multirow[t]{2}{*}{ Go/no-go } & RT & $44(32-70)$ & $53(20-70)$ & $47(30-60)$ & $41(30-64)$ & $66(20-72)$ & $65(29-98)$ & 40 & 44 \\
\hline & Errors & $0(0-1)$ & $0(0-1)$ & $0(0-2)$ & $0(0-2)$ & $0(0-1)$ & $0(0-1)$ & 0 & 0 \\
\hline \multirow[t]{2}{*}{ Incompatibility } & RT & $39(37-63)$ & $36(20-66)$ & $36(20-66)$ & $36.5(20-64)$ & $48(20-65)$ & $47(20-67)$ & 33 & 31 \\
\hline & Errors & $1(0-4)$ & $3(1-12)$ & $3(0-12)$ & $1.5(0-8)$ & $3(1-6)$ & $3(1-6)$ & 2 & 4 \\
\hline \multirow{2}{*}{ Flexibility } & RT & $57(46-70)$ & $48(28-66)$ & $48(28-66)$ & $48.5(28-61)$ & $56(34-72)$ & $57(34-99)$ & 53 & 51 \\
\hline & Errors & $2(0-5)$ & $2(0-5)$ & $2(0-5)$ & $1.5(0-5)$ & $3(0-13)$ & $1(0-9)$ & 1 & 0 \\
\hline \multirow[t]{3}{*}{ Vigilance } & RT & $53(41-66)$ & $54(44-63)$ & $56(39-64)$ & $53(42-80)$ & $51(39-56)$ & $48(24-66)$ & 56 & 64 \\
\hline & Errors & $3(0-11)$ & $2.5(1-4)$ & $0(0-3)$ & $1(0-2)$ & $1(0-3)$ & $0(0-0)$ & 2 & 0 \\
\hline & Omissions & $2(1-4)$ & $1.5(0-7)$ & $1.5(0-10)$ & $2.5(0-11)$ & $2(0-15)$ & $2(0-19)$ & 9 & 2 \\
\hline
\end{tabular}

Values for reaction time (RT) are T scores based on a normative sample ( $\mathrm{n}=200$ healthy subjects). 
Table 5 Changes of performance after the second training

\begin{tabular}{lllll}
\hline & & \multicolumn{2}{l}{ Training group $p$ values } \\
\cline { 3 - 4 } Control test (TAP) & & Alertness & $\begin{array}{l}\text { Divided } \\
\text { attention }\end{array}$ & $\begin{array}{c}\text { Selective } \\
\text { attention }\end{array}$ \\
\hline Alertness: & & & & \\
Simple & RT & 0.414 & 0.382 & 0.059 \\
Cued & RT & 0.462 & 0.777 & 0.062 \\
Divided attention & RT & 1.0 & 0.799 & 0.753 \\
& Errors & 0.655 & 0.180 & 0.578 \\
Selective attention: & Omissions & 0.257 & 0.206 & 0.395 \\
Go/no-go & & & & \\
Incompatibility & RT & 0.465 & 0.332 & 0.089 \\
& Errors & 1.0 & 0.564 & 0.564 \\
Flexibility & RT & 0.655 & 0.888 & 0.599 \\
Vigilance & Errors & 0.180 & 0.642 & 0.462 \\
& RT & 0.414 & 0.339 & 0.173 \\
& Errors & 0.198 & 0.798 & 0.173 \\
& RT & 0.144 & 0.541 & 0.499 \\
& Errors & 0.198 & 0.914 & 0.066 \\
& Omissions & 1.0 & 0.574 & 0.136 \\
\hline
\end{tabular}

Because of the small sample size, no statistical analysis was done for the vigilance group. $\mathrm{p}$ Values are differences between $\mathrm{T}_{4}$ and $\mathrm{T}_{5}$.

mation ("focused attention deficit" according to Shiffrin and Schneider ${ }^{35}$ ). The interference tendency is tested by a stimulus-response incompatibility. Arrows pointing to the left or the right are presented on the left or the right of a fixed point. The subject is required to press a key on the left or the right, depending on the direction of the arrow-irrespective of the side of presentation. If the side of presentation and the side of response are in accordance, the condition is classified as compatible, otherwise incompatible.

Flexibility

Selective attention presupposes both the capacity of focusing on one aspect of a situation and the ability to change the focus of attention. ${ }^{19}{ }^{36}$ In this examination the flexibility of focused attention is tested by mental alternation between two sets of targets (letters or numbers). Therefore a letter and a number are presented simultaneously. Between trials the position of the letter and the number varies randomly. From one presentation to the next, the target changes from letter to number and vice versa. The subject has to push the button on the side of the target.

\section{Vigilance}

Vigilance tests examine the ability to sustain and focus attention in itself. ${ }^{33}$ The relevant aspects are time on task effects, lapses of attention, and intraindividual variability. ${ }^{32}$ In the present examination a thick vertical line swings up and down with a varying amplitude. The subject has to detect a clearly larger swing upwards. The task is run with a low event rate of critical stimuli (by contrast with monitoring tests with high frequency of targets).

All the tasks consist of simple and easily distinguishable stimuli that the patients react to by a simple motor response. Thus the interference of other neurological impairments such as hemiparesis, ataxia, and visual disorders is very limited.

Evaluation of everyday attentional problems was done with the FEDA, ${ }^{37}$ a self rating inventory assessing three factors disclosed by factor analysis: distractibility and slowing of mental processes (scale 1, 13 items), fatigue and slowing concerning practical activities (scale 2, eight items), and decrease of drive (scale 3, six items).

Table 6 Performance changes after the first $\left(T_{4}-T_{1-3}\right)$ training, separated for patients with specific and non-specific training

\begin{tabular}{|c|c|c|c|c|c|c|c|c|c|}
\hline & \multirow{2}{*}{\multicolumn{2}{|c|}{ Alertness }} & \multirow{2}{*}{\multicolumn{3}{|c|}{ Divided attention }} & \multicolumn{4}{|c|}{ Selective attention } \\
\hline & & & & & & \multicolumn{2}{|l|}{ Go/no-go } & \multicolumn{2}{|c|}{ Incompatibility } \\
\hline & Simple RT & Cued RT & $R T$ & Errors & Omissions & $R T$ & Errors & $R T$ & Errors \\
\hline \multicolumn{10}{|c|}{ Specific trained patients: } \\
\hline Mean (s) & $9.86(9.41)$ & $6.71(9.12)$ & $4.63(4.14)$ & $-0.63(1.3)$ & $-0.5(2)$ & $11.83(7.73)$ & $-0.33(0.52)$ & $9.5(6.29)$ & $1(3.41)$ \\
\hline Median & 10 & 4 & 5 & -0.5 & 0 & 12 & 0 & 10.5 & \\
\hline Range & 1 to 28 & -5 to 24 & -1 to 11 & -2 to 1 & -5 to 1 & 3 to 23 & -1 to 0 & -1 to 16 & -3 to 7 \\
\hline \multicolumn{10}{|c|}{ Non-specific trained patients: } \\
\hline Mean (s) & $1.13(6.84)$ & $1.63(5.28)$ & $2.07(7.46)$ & $0.2(1.08)$ & $-0.33(1.84)$ & $4.35(9.25)$ & $0.18(0.64)$ & $2.06(4.68)$ & $-0.71(2.52)$ \\
\hline Median & 0 & 1 & 1 & 0 & 0 & 2 & 0 & 1 & -1 \\
\hline Range & -8 to 15 & -6 to 15 & -10 to 14 & -2 to 2 & -4 to 3 & -8 to 24 & -1 to 2 & -6 to 11 & -7 to 3 \\
\hline $\mathrm{p}$ Values & $0.027^{\star}$ & 0.07 & 0.40 & 0.14 & 0.82 & $0.0495^{\star}$ & 0.069 & $0.022^{\star}$ & 0.32 \\
\hline
\end{tabular}

Values for reaction time (RT) are T scores.

Because of the small sample size, no statistical analysis was done for the vigilance group.

^Significant.

Table 7 Performance changes after the second $\left(T_{5}-T_{\downarrow}\right)$ training, separated for patients with specific and non-specific training

\begin{tabular}{|c|c|c|c|c|c|c|c|c|c|}
\hline & \multirow{2}{*}{\multicolumn{2}{|c|}{ Alertness }} & \multirow{2}{*}{\multicolumn{3}{|c|}{ Divided attention }} & \multicolumn{4}{|c|}{ Selective attention } \\
\hline & & & & & & \multicolumn{2}{|l|}{ Go/no-go } & \multicolumn{2}{|l|}{ Incompatibility } \\
\hline & Simple $R T$ & Cued $R T$ & $R T$ & Errors & Omissions & $R T$ & Errors & $R T$ & Errors \\
\hline \multicolumn{10}{|c|}{ Specific trained patients: } \\
\hline Mean (s) & $3.0(7.26)$ & $3.25(5.5)$ & $-0.2(9.51)$ & $-0.3(.68)$ & $-0.9(2.13)$ & $8.43(10.18)$ & $0.14(0.69)$ & $0.286(5.62)$ & $0.43(1.5)$ \\
\hline Median & 2.5 & 3.5 & 2 & 0 & -0.5 & 4 & 0 & -1 & 0 \\
\hline Range & -5 to 12 & -2 to 8 & -19 to 12 & -2 to 0 & -5 to 3 & -5 to 26 & -1 to 1 & -4 to 12 & -2 to 3 \\
\hline \multicolumn{10}{|c|}{ Non-specific trained patients: } \\
\hline Mean (s) & $3.0(7.32)$ & $2.6(8.03)$ & $-1.8(12.4)$ & $-0.15(1.14)$ & $-0.08(2.93)$ & $-3.07(10.54)$ & $0.06(0.44)$ & $0(5.96)$ & $-0.563(3)$ \\
\hline Median & 1.5 & 1.5 & -0.5 & 0 & 0 & -4 & 0 & 0 & 0 \\
\hline Range & -4 to 29 & -5 to 32 & -27 to 20 & -2 to 2 & -6 to 7 & -24 to 16 & -1 to 1 & -15 to 8 & -10 to 4 \\
\hline $\mathrm{p}$ Values & 0.97 & 0.61 & 0.64 & 0.72 & 0.45 & $0.04^{\star}$ & 0.69 & 0.67 & 0.47 \\
\hline
\end{tabular}

Values for reaction time (RT) are T scores.

Because of the small sample size, no statistical analysis was done for the vigilance group.

${ }^{\star}$ Significant. 
TREATMENT/TRAINING PROGRAMMES

Training of alertness

This task requires the patient to control the speed of a car driving along a variable track, tracking as fast as possible, but coping with various dangerous situations such as stopping in front of obstacles or at crossroads.

\section{Training of divided attention}

In this programme a cockpit is simulated, in which the patient has to monitor two independent stimulus sequences simultaneously. $\mathrm{He}$ has to respond to critical stimuli or sequences of stimuli in either or both of two independent stimulus "channels" (visualauditive or visual-visual).

Training of selective attention

This exercise resembles trap shooting and requires rapid responses to critical stimuli moving across the monitor screen.

Training of vigilance

In this task the patient has to monitor a radar screen and detect the appearance of objects or the changing of speed of objects already present.

In all the programmes the difficulty of the task is adapted automatically to the performance of the patient. The level of difficulty may, however, also be regulated by the trainer or the trainee himself. After each training session the patients can get feedback about reaction times, number and type of errors, and the achieved level of difficulty. For each task the patients have to press one or two big response buttons,

Table 6 Continued

\begin{tabular}{|c|c|c|c|c|}
\hline \multicolumn{2}{|l|}{ Flexibility } & \multicolumn{3}{|l|}{ Vigilance } \\
\hline$R T$ & Errors & $R T$ & Errors & Omissions \\
\hline $\begin{array}{l}10.67(9.37) \\
7.5 \\
2 \text { to } 28\end{array}$ & $\begin{array}{l}-4(6.42) \\
-1.5 \\
-16 \text { to } 2\end{array}$ & $\begin{array}{l}3(0) \\
3\end{array}$ & $\begin{array}{l}-0.5(0.71) \\
-0.5 \\
-1 \text { to } 0\end{array}$ & $\begin{array}{l}-5.0(7.07) \\
-5 \\
-10 \text { to } 0\end{array}$ \\
\hline $\begin{array}{l}4.88(3.14) \\
4 \\
1 \text { to } 12 \\
0.11\end{array}$ & $\begin{array}{l}-0.82(4.61) \\
0 \\
-8 \text { to } 8 \\
0.32\end{array}$ & $\begin{array}{l}1.43(5.43) \\
0 \\
-7 \text { to } 12\end{array}$ & $\begin{array}{l}0.52(3.68) \\
0 \\
-9 \text { to } 10\end{array}$ & $\begin{array}{l}0.05(2.58) \\
0 \\
-5 \text { to } 7\end{array}$ \\
\hline
\end{tabular}

Table 7 Continued

\begin{tabular}{|c|c|c|c|c|}
\hline \multicolumn{2}{|l|}{ Flexibility } & \multicolumn{3}{|l|}{ Vigilance } \\
\hline$R T$ & Errors & $R T$ & Errors & Omissions \\
\hline $\begin{array}{l}5.29(10.23) \\
2\end{array}$ & $\begin{array}{l}-2.86(4.9) \\
-2\end{array}$ & 8 & -2 & \\
\hline-4 to 27 & -11 to 4 & 8 & -2 & -7 \\
\hline $\begin{array}{l}0.33(3.74) \\
0 \\
-6 \text { to } 7 \\
0.2\end{array}$ & $\begin{array}{l}0.38(2.34) \\
0 \\
-3 \text { to } 5 \\
0.09\end{array}$ & $\begin{array}{l}-0.33(9.37) \\
-2 \\
-15 \text { to } 24\end{array}$ & $\begin{array}{l}-0.96(2.2) \\
0 \\
-7 \text { to } 2\end{array}$ & $\begin{array}{l}0.77(3.66) \\
0 \\
-8 \text { to } 10\end{array}$ \\
\hline
\end{tabular}


were analysed for significance using the Wilcoxon signed ranks test.

\section{Results}

A total of 22 outpatients with multiple sclerosis aged between 25 and 70 years completed the study (table 1 shows their details). As proposed, subgroups of patients with multiple sclerosis showing different patterns of attentional impairment could be separated. Originally we aimed to balance the order of the training programmes - that is, each kind of training should be at the first and second place with the same frequency. For that reason the attentional function trained first is not automatically identical with the worst or weakest function. Because of the combination of the impairments found in our patients (the affected dimensions were not distributed equally) a balanced order of the training programmes was not possible. In the end only nine of the 12 possible combinations occurred. Therefore we were not able to examine directly any kind of transfer (positive or negative) from the first to the second training period. Because the patients entered the study consecutively this unbalanced distribution was not anticipated. This resulted in different sample sizes in the two training periods.

Tables 2 and 3 show the performance of the different training groups in each of the control tests before and after the first training period. Significant improvements of performance for the domains alertness and divided attention as well as an increased performance in the go/no-go paradigm as an aspect of selective attention could only be achieved by the respective training programmes and not by the others. For selective attention, performance in all the subtests of function could only be improved by the specific training also. In the subtest Incompatibility reaction times could also be improved by an alertness training, which aims at increasing the speed of reaction. As a non-specific effect a better performance in the subtest flexibility was achieved by all of the training programmes.

Tables 4 and 5 summarise the results of the second training period. No additional improvement of performance could be shown.

Tables 6 and 7 show the comparison of the change of performance between the specifically trained and all the other patients for the first and second training period (comparison between groups). As the results of the corresponding $U$ tests for the first training show, for the domains alertness and selective attention the specifically trained patients showed a significantly higher increase of performance in the respective control tests (tonic alertness, go/no-go, incompatibility) compared with the non-specific group. After the second training period only the "selective attention" group turned the training to its advantage. This led to significantly greater change of performance in the subtest go/ no-go.

Comparing the performance in the specifically trained attention domain after completion of the first training with the performance in the follow up examinations $\left(T_{5}-T_{7}\right)$ disclosed no

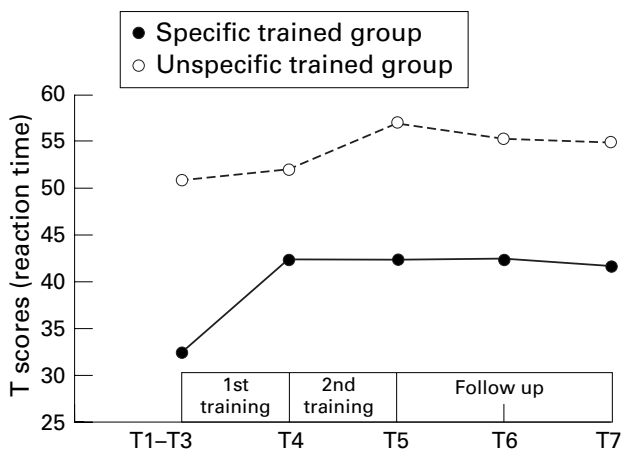

Figure 2 TAP: tonic alertness. Effects of first training (mean scores).

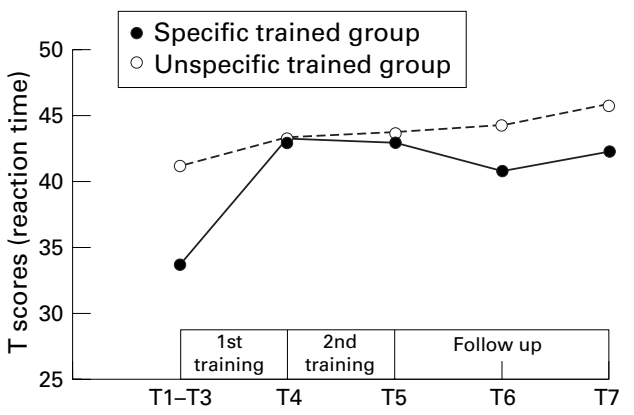

Figure 3 TAP: incompatibility. Effects of first training (mean scores).

significant differences (Friedman two way ANOVA), indicating stable treatment effects for at least nine weeks (figs 2 and 3).

Concerning the impact of this stimulation training on daily functioning there are significant differences in FEDA scores between baseline and post-treatment assessment. Patients reported less fatigue and slowing of physical activities $(p=0.03)$ as well as decreased distractibility and a lower degree of slowing of mental processes $(p=0.04$, Wilcoxon signed ranks test).

The mean BDI score (8.33) of the total sample before the start of treatment was not in the range of clinically relevant depression and did not differ statistically from the mean values after completion of the training (Wilcoxon signed ranks test).

In almost all patients EDSS scores remained stable during the observation period. In one patient the EDSS score changed from 4.0 at baseline to 3.0 during training and follow up. Disability scores of another patient changed from 2.5 to 3.5 , respectively.

\section{Discussion}

Different aspects of attention such as alertness, divided attention, selective attention, and sustained attention had been assessed in patients with multiple sclerosis. Most of the patients did not show a generalised decrease of performance, but a rather selective impairment of one or more of these attentional domains. As several authors stated ${ }^{40-43}$ these results might reflect factors other than attention deficits, as for example, oculomotor, visual, or motor impairments. The influence of such confounding variables on the results of our study seems to be limited for several reasons. Firstly, as 
could be seen in stable EDSS scores in our sample, there was no significant change of physical impairment and disability during the study period. Furthermore, the tasks of the TAP do not place heavy demands on fine visual acuity, motor speed, or coordination. All the tasks require the same simple motor action such as pressing a big button. Therefore the fact of selectively reduced performance in different attention tasks should indicate real and specific impairments of attentional domains - that is, alertness, and divided and selective attention.

The aim of this study was to evaluate the efficacy of a stimulation therapy-namely, specific computer based retraining of the four attention domains described above. Therefore, dependent on the pattern of attentional impairment, patients were assigned to specific treatments. The results support the claim that different aspects of attentional impairment should be treated specifically. This applies at least to the domains alertness and selective attention and probably to divided attention as well. In view of the small sample size for the domain vigilance no statement was possible. Our results confirm the findings of Sturm et $a l,{ }^{27}$ who applied the same specific treatment to a group of patients with stroke and were also able to detect selective effects of this training.

In the present study significant reduction of reaction time in the domain selective attention was also seen after non-specific training-that is, training of alertness - which aims at an increase of reaction speed. These findings indicate that complex attentional demands contain aspects of basic attention functions in addition to specific components. These can be trained by programmes that try to improve general activation. Coping with a task assessing tendencies of interference and focused attention requires a sufficient degree of activation (tonic alertness). Analysis of the results concerning alertness discloses significant improvement in trials without a warning signal compared with trials with a warning signal. This suggests that especially the aspect of tonic alertness can be influenced by a specific training.

Interestingly, the described improvements translate exclusively in shorter reaction times. Qualitative aspects of performance remained stable during the study period. From the beginning most of the subjects showed only few omissions and rather low error rates, possibly the result of a strategy which in the face of limited attentional capacity might force reduction of processing speed. Therefore, another effect of training could be seen in the fact that the patients kept their high number of correct responses despite a significant increase of speed. In conclusion, a specific training seems to improve intensity and selectivity aspects of attention.

In the second training period a significant improvement could only be shown for the domain selective attention. As our patient sample had rather mild cognitive impairment a ceiling effect cannot be excluded as a result of a non-specific effect (general activation, increased motivation and mood, etc) of the first training. This finding would imply that only one training period would suffice, at least for patients with mild attention deficits, in which the most deteriorated function is trained. The limited effect of the second training could be also explained by the lack of re-evaluation of indication. The decision as to which function should be trained next was taken before the start of treatment. To be able to take into account some non-specific effects of the first training resulting in an increase of performance in different attention domains this decision should have been revised after the end of the first training period. Another explanation for the lack of significant improvement in the second training cycle may be that patients with multiple sclerosis only have a limited ability to learn.

As Van Zomeren and Brouwer ${ }^{32}$ noted, the effect of such a computer based retraining of attention functions can be measured in three ways: at the task level, at the level of task related psychometric tests, and at the level of daily functioning. As in most of the studies that systematically measured improvement on trained tasks, in the present study patients also showed progress. This was evident in an increasing level of difficulty or gradual increase in the number of correct responses. As this could be interpreted as a trivial practice effect, indicating that patients can learn to carry out specific tasks, progress on trained tasks remains unsatisfactory. Therefore psychometric tests have to be used to determine generalisation. In this study the specific training programmes and control tests followed the same paradigm; however, the tasks were different. Because significant improvement can be selectively seen in the specifically trained functions, the increase of performance cannot be due to practice effects, spontaneous recovery, or improved mood, because these should have led to visible improvement in all of the impaired attentional functions.

To determine generalisation to other cognitive functions we additionally used a comprehensive neuropsychological test battery before and after the training period. The preliminary results suggest an increase of performance in tests of reasoning and abstraction (data not shown).

Undoubtedly, the most important question is whether the presented stimulation training has an impact on daily functioning. The analysis of the self rating inventory for every day attentional problems (FEDA) disclosed less distractibility and fatigue as well as a lower degree of slowing of both mental processes and physical activities. Furthermore, in a final interview, many of the patients pointed out that the experience of improving cognitive performance (based on both the trainer's feedback and their own perceptions) was important for their sense of self esteem, especially with respect to their progressive disease, involving mostly deterioration and rarely improvement of physical and mental functions.

In conclusion, our results underline the importance of a detailed assessment of attention functions in patients with multiple 
sclerosis to identify specific deficits in the attention domains described. Such an evaluation allows us to target the neuropsychological intervention-for example, to administer a specific computer assisted retraining that has shown efficacy in this study. In general, the training tasks should resemble daily attention situations as closely as possible. In this context the prospects of virtual reality offer interesting possibilities. To optimise rehabilitation outcome a combination with strategy training ${ }^{44-47}$ would be useful.

We gratefully acknowledge the use of a provisional version of the training software AIXTENT, which was made available to us by Dr Walter Sturm, Neurological Clinic, Medical Faculty of the RWTH Aachen, Germany. We also thank Professor AJ Steck, Department of Neurology, University Hospital Basel, for Department of Neurology, University Hospital Basel, for continuous support and his consent to include two of his patients. The study was supported by research grants from the the Swiss Multiple Sclerosis Society.

1 Peyser JM, Rao SM, LaRocca NG, et al. Guidelines for neuropsychological research in multiple sclerosis. Arch Neurol 1990;47:94-7.

2 McIntosh Michaelis SA, Roberts MH, Wilkinson SM, et al. The prevalence of cognitive impairment in a community survey of multiple sclerosis. Br F Clin Psychol 1991;30:33348.

3 Ron MA, Feinstein A. Korsakoff's psychosis in the presence of multiple sclerosis: an unusual cognitive state [letter]. $\mathscr{f}$ Neurol Neurosurg Psychiatry 1990;53:625.

4 Rao SM. Neuropsychology of multiple sclerosis. Curr Opin Neurol 1995;8:216-20.

5 Rao SM. Neuropsychology of multiple sclerosis: a critical review. F Clin Exp Neuropsychol 1986;8:503-42.

6 Rao SM, St Aubin Faubert P, Leo GJ. Information processing speed in patients with multiple sclerosis. $\mathcal{F}$ Clin Exp Neuropsychol 1989;11:471-7.

7 Franklin GM, Nelson LM, Filey CM, et al. Cognitive loss in multiple sclerosis. Case reports and review of the literature. Arch Neurol 1989;46:162-7.

8 Rao SM, Leo GJ, Bernardin L, et al. Cognitive dysfunction in multiple sclerosis. I. Frequency, patterns, and prediction [see comments]. Neurology 1991;41:685-91.

9 Ron MA, Callanan MM, Warrington EK. Cognitive abnormalities in multiple sclerosis: a psychometric and MR study. Psychol Med 1991;21:59-68.

10 Albert ML, Feldman RG, Willis AL. The "subcortical dementia" of progressive supranuclear palsy. $\mathcal{F} \mathrm{Neurol} \mathrm{Neu}$ rosurg Psychiatry 1974;37:121-30.

11 Cummings JL, Benson DF. Subcortical dementia: review of an emerging concept. Arch Neurol 1984;41:847-79.

12 Pozzilli C, Bastianello S, Padovani A, et al. Anterior corpus callosum atrophy and verbal fluency in multiple sclerosis. Cortex 1991;27:441-5.

13 Wallace GL, Holmes S. Cognitive-linguistic assessment of individuals with multiple sclerosis. Arch Phys Med Rehabil 1993;74:637-43.

14 Rao SM, Leo GJ, Ellington L, et al. Cognitive dysfunction in multiple sclerosis. II. Impact on employment and social
functioning [see comments]. Neurology 1991;41:692-6.

15 Smits RCF, Emmen HH, Bertelsmann FW, et al. The effects of 4-aminopyridine on cognitive function in patients with of 4 -aminopyridine on cognitive function in patients with
multiple sclerosis: a pilot study. Neurology 1994;44:1701-5.

16 Foley FW, Dince WM, Bedell JR, et al. Psychoremediation of communication skills for cognitively impaired person with multiple sclerosis. F Neurol Rehabil 1994;8:165-76.

17 Jonnsson A, Korfitzen EM, Heltberg A, et al. Effects of neuropsychological treatment in patients with multiple sclerosis. Acta Neurol Scand 1993;88:394-400.

18 Posner MI, Boies SJ. Components of attention. Psychol Rev 1971;78:391-408.

19 Zubin J. Problems of attention in schizophrenia. In: Kietzman ML, Sutton S, Zubin J, eds. Experin approach to psychopathology. New York: Academic Press, 1975

20 Posner MI, Rafal RD. Cognitive theories of attention and the rehabilitation of attentional deficits. In: Meier RJ, Benton AL, Diller L, eds. Neuropsychological rehabilitation. Edinburgh: Churchill Livingstone, 1987:182-201.
21 Davies DR, Jones DM, Taylor A. Selective and sustained attention cases: individual and group differences. In: Parasuraman R, Davis R, eds. Varieties of attention. Orlando: Academic Press, 1984:395-447.

22 Poser U, Kohler J, Sedlmeier P, et al. Evaluierung eines neuropsychologischen Funktionstrainings bei Patienten mit kognitiver Verlangsamung nach Schädelhirntrauma. Zeitschrift für Neuropsychologie 1992;3:3-24.

23 Ponsford JL, Kinsella G. Evaluation of a remedial programme for attentional deficits following closed head injury. f Clin Exp Neuropsychol 1988;10:693-708.

24 Ben-Yishay Y, Piasetzky EB, Rattok J. A systematic method for ameliorating disorders in basic attention. In: Meier MJ, Benton AL, Diller L, eds. Neuropsychological Rehabilitation Edinburgh: Churchill Livingstone, 1987.

25 Sturm W, Willmes K. Efficacy of a reaction training of various attentional and cognitive functions in stroke patients. Neuropsychological Rehabilitation 1991;1:259-80.

26 Sturm W, Hartje W, Orgass B, Willmes K. Computerassisted rehabilitation of attention impairments. In: Stachowiak FJ, De Bleser R, eds. Developments in the assessment and rehabilitation of brain-damaged patients. Perspectives from a European concerted action. Tübingen: Gunter Narr Verlag, 1993:49-52

27 Sturm W, Hartje W, Orgass B, et al. Effektivität eines computergestützten Trainings von vier Aufmerksamkeitsfunktionen. Zeitschrift für Neuropsychologie 1994;5:15-28.

28 Poser CM, Paty DW, Scheinberg LC, et al. New diagnostic criteria for multiple sclerosis: guidelines for research protocols. Ann Neurol 1983;13:227-31.

29 Zimmermann P, Fimm B. Testbatterie zur Aufmerksamkeitsprüfung (TAP) Version 1.02c. Psytest, Herzogenrath: Vera Fimun, 1994.

30 Margolin DI. Cognitive neuropsychology in clinical practice. New York: Oxford University Press, 1992

31 Posner MI. Chronometric explorations of mind. Hillside, NJ: Lawrence Erlbaum Associates, 1978.

32 van Zomeren AH, Brouwer WH. Clinical neuropsychology of attention. New York: Oxford University Press, 1994.

33 Lezak MD. Neuropsychological assessment. New York: Oxford University Press, 1995.

34 Kahneman D. Attention and effort. Englewood Cliff, New Jersey: Prentice Hall, 1973.

35 Shiffrin RM, Schneider W. Controlled and automatic human information processing: perceptual learning, automatic attending and a general theory. Psychol Rev 1977;84: $127-90$.

36 Sohlberg MM, Mateer CA. Introduction to cognitive rehabilitation. New York Guilford Press, 1989.

37 Zimmermann P, Messner C, Poser U, et al. Ein Fragebogen erlebter Defizite der Aufmerksamkeit (FEDA) [abstract]. 1993.

38 Sturm W. Neuropsychologische Therapieeinsätze bei Störungen intellektueller Funktionen, Wahrnehmungsstörungen, Gedächtnisbeeinträchtigungen und Aufmerksamkeitsstörungen. In: Poeck K, ed. Klinische Neuropsychologie. Stuttgart: Thieme, 1989:371-99.

39 Beck AT. Beck depression inventory (German ed). Bern: Hans Huber, 1994.

40 Peyser JM, Poser CM. Neuropsychological correlates of multiple sclerosis. In: Filskov SB, Boll TJ, eds. Handbook of clinical neuropsychology. Vol 2. New York: Wiley, 1986:36497.

41 Jennekens Schinkel A, Laboyrie PM, Lanser JB, et al. Cognition in patients with multiple sclerosis after four years. $\mathcal{F}$ Neurol Sci 1990;99:229-47.

42 Beatty WW, Scott JG. Issues and developments in the neuropsychological assessment of patients with multiple sclerosis. Special issue: comprehensive evaluation of outcome of care in multiple sclerosis. 7 Neurol Rehabil 1993;7:87-97.

43 Stenager E, Knudsen L, Jensen K. Multiple sclerosis: methodological aspects of cognitive testing. Acta Neurol Belg 1994;94:53-6.

44 Sullivan MJ, Edgley K, Dehoux E. A survey of multiple sclerosis: I. Perceived cognitive problems and compensatory strategy use. Can f Rehabil 1990;4:99-105.

45 Sullivan MJL, Dehoux E, Buchanan DC. An approach to cognitive rehabilitation in multiple sclerosis. Can $\mathcal{F}$ Rehabil 1989;3:77-85.

46 LaRocca NG. A rehabilitation perspective. In: Rao SM, ed. Neurobehavioral aspects of multiple sclerosis. New York: Oxford University Press, 1990:215-29.

47 Bennett T, Dittmar C, Raubach S. Multiple sclerosis: cognitive deficits and rehabilitation strategies. Cognitive Rehabilitation 1991;9:18-23. 